\title{
Identifying the relevant population for neoadjuvant chemo-hormonal therapy combined with radical prostatectomy
}

\author{
Géraldine Pignot, Jochen Walz
}

Service de Chirurgie Oncologique 2, Institut Paoli-Calmettes, Marseille, France

Correspondence to: Géraldine Pignot. Service de Chirurgie Oncologique 2, Institut Paoli-Calmettes, Marseille, France. Email: pignotg@ipc.unicancer.fr.

Provenance and Peer Review: This article was commissioned and reviewed by the Section Editor Dr. Xiao Li, MD (Department of Urology, Jiangsu Cancer Hospital \& Jiangsu Institute of Cancer Research \& Nanjing Medical University Affiliated Cancer Hospital, Nanjing, China).

Comment on: Pan J, Chi C, Qian H, et al. Neoadjuvant chemohormonal therapy combined with radical prostatectomy and extended PLND for very high risk locally advanced prostate cancer: A retrospective comparative study. Urol Oncol 2019;37:991-8.

Submitted Dec 09, 2019. Accepted for publication Dec 30, 2019.

doi: $10.21037 /$ gs.2019.12.22

View this article at: http://dx.doi.org/10.21037/gs.2019.12.22

High-risk localized PCa account for about $15 \%$ of cases at diagnosis (1) and it is particularly important to establish an appropriate treatment strategy for these patients, considering a multimodal approach and including both local and systemic therapies. Radical prostatectomy (RP) may be an option for selected patients with high-risk localized prostate cancer with an acceptable cancer-specific mortality $(10-15 \%)$ at 10 years; however, oncological outcomes are decreasing for the subgroups of highest risk patients who have $\geq$ pT3 disease, Gleason score $\geq 8$, and lymph node invasion. For these patients, the risk of recurrence is up to $70 \%$ at 10 years after RP (2).

We have read with interest the publication of Pan et al. entitled "Neoadjuvant chemohormonal therapy combined with RP and extended PLND for very high risk locally advanced prostate cancer: a retrospective comparative study" (3). In this article, the authors have clearly addressed the problem of identifying the relevant patient population. Indeed, there is probably a very high-risk population that really benefits from perioperative strategies. This multimodal approach probably offers the greatest chance of cure for men who may harbor occult metastatic disease.

The rationale for neoadjuvant systemic therapy is to reduce tumor volume, facilitating a complete surgical resection and reducing the risk of positive margins. It can also provide early systemic control of microscopic metastatic disease, thereby delaying time to progression and/or recurrence.

Data remains controversial regarding whether a neoadjuvant strategy may or may not benefit these patients with high-risk localized prostate. Data from phase 2 clinical trials of neoadjuvant chemotherapy without androgen deprivation therapy (ADT) showed no improvement in clinical outcomes (4-7). On the other hand, there is no evidence for a benefit of neoadjuvant $\mathrm{ADT}$ alone prior RP [biochemical progression-free survival (bPFS) and overall survival (OS)] although there is a tendency toward improved pathological results (particularly positive margins) compared to RP alone (8).

Thus, combined strategy with docetaxel-based chemohormonal therapy may have a role in eliminating preexisting ADT-resistant tumor cells in the neoadjuvant setting. This chemo-hormonal strategy has already been tested before RP and has shown low rates of pathological complete response (less than $10 \%$ in most studies) (9-11). Recently, the prospective randomized phase III trial, Cancer and Leukemia Group B (CALGB) 90203 evaluated the benefit of neoadjuvant chemo-hormonal treatment in men with high-risk clinically localized prostate cancer and showed that neoadjuvant ADT plus docetaxel followed by RP did not increase 3-year bPFS compared with RP alone (12). However, given that a substantial portion of the patients in this study received additional treatment in a non-randomized fashion outside of the clinical trial, it is unknown what effect, if any, this may have had on OS.

Compared to CALGB 90203, the chemo-hormonal treatment arm in the current study had a more advanced clinical stage $(98.3 \%$ of T3-T4 tumors and $55 \%$ of positive 
lymph node disease). Indeed, the authors address the issue of very high-risk patients defined as a clinical stage more than cT3a, or primary Gleason pattern 5 or $\geq 5$ cores with Gleason sum 8 to 10 , or PSA $\geq 50 \mathrm{ng} / \mathrm{mL}$, or with pelvic metastatic lymph node involvement. It should be noted that only $48 \%$ of patients had an undetectable postoperative PSA, and $81 \%$ of patients with undetectable PSA experienced early biochemical recurrence (median time of 9 months) if RP alone, thus justifying salvage therapy. This subpopulation therefore has a particularly poor prognosis and a neoadjuvant chemo-hormonal combination is more likely to have a benefit in this context. Although the followup is still insufficient, especially for the chemo-hormonal treatment arm, and despite the retrospective design of the study, the oncological outcomes are interesting in terms of bPFS. OS data will incorporate the impact of any adjuvant or salvage postoperative therapy.

Beside neoadjuvant strategy, several trials have assessed the chemo-hormonal strategy in an adjuvant setting after RP and showed no improvement in OS (13). Nevertheless, these studies included heterogeneous patient populations.

Finally, while the authors probably identify the most relevant population justifying a neoadjuvant or adjuvant chemo-hormonal strategy, the question of optimal local treatment remains. A very high-risk localized prostate cancer may probably be discussed for radiation therapy in combination with hormonal treatment, especially if PSA $>50 \mathrm{ng} / \mathrm{mL}$ or lymph node involvement. A metaanalysis of 11 trials evaluating docetaxel in men with nonmetastatic prostate cancer, including GETUG-12, RTOG 0521, and STAMPEDE, showed no benefit in OS with the addition of docetaxel to radiotherapy in combination with hormonal treatment (14). Several trials are still ongoing to assess the benefit of chemotherapy in association with radiotherapy and hormonal treatment, such as the phase III PEACE 2 (GETU-AFU 23) trial that evaluates four cycles of neoadjuvant cabazitaxel and/or pelvic radiotherapy in combination with $\mathrm{ADT}$ and prostate radiotherapy.

Neoadjuvant or adjuvant strategies also call into question about the efficacy of subsequent therapies in case of metastatic progression. In the ancillary study of CALGB 90203 , it is remarkable that there is a heterogeneity of treatment response with some upregulation of AR-V7 expression as well as a subset of neuroendocrine and plasticity genes, which could probably serve as potential early molecular markers of resistance (15).

The two challenges of the next few years will be to integrate next-generation hormone therapy into this neoadjuvant/adjuvant setting and to identify patients who could really benefit from such a strategy by avoiding unnecessary toxicities.

\section{Acknowledgments}

Funding: None.

\section{Footnote}

Conflicts of Interest: Both authors have completed the ICMJE uniform disclosure form (available at http://dx.doi. org/10.21037/gs.2019.12.22). The authors have no conflicts of interest to declare.

Ethical Statement: The authors are accountable for all aspects of the work in ensuring that questions related to the accuracy or integrity of any part of the work are appropriately investigated and resolved.

Open Access Statement: This is an Open Access article distributed in accordance with the Creative Commons Attribution-NonCommercial-NoDerivs 4.0 International License (CC BY-NC-ND 4.0), which permits the noncommercial replication and distribution of the article with the strict proviso that no changes or edits are made and the original work is properly cited (including links to both the formal publication through the relevant DOI and the license). See: https://creativecommons.org/licenses/by-nc-nd/4.0/.

\section{References}

1. Cooperberg MR, Broering JM, Carroll PR. Time trends and local variation in primary treatment of localized prostate cancer. J Clin Oncol 2010;28:1117-23.

2. Donohue JF, Bianco FJ Jr, Kuroiwa K, et al. Poorly differentiated prostate cancer treated with radical prostatectomy: long-term outcome and incidence of pathological downgrading. J Urol 2006;176:991-5.

3. Pan J, Chi C, Qian H, et al. Neoadjuvant chemohormonal therapy combined with radical prostatectomy and extended PLND for very high risk locally advanced prostate cancer: A retrospective comparative study. Urol Oncol 2019;37:991-8.

4. McKay RR, Choueiri TK, Taplin ME. Rationale for and review of neoadjuvant therapy prior to radical prostatectomy for patients with high-risk prostate cancer. Drugs 2013;73:1417-30. 
5. Cha EK, Eastham JA. Chemotherapy and novel therapeutics before radical prostatectomy for highrisk clinically localized prostate cancer. Urol Oncol 2015;33:217-25.

6. Pietzak EJ, Eastham JA. Neoadjuvant Treatment of HighRisk, Clinically Localized Prostate Cancer Prior to Radical Prostatectomy. Curr Urol Rep 2016;17:37.

7. Lou DY, Fong L. Neoadjuvant therapy for localized prostate cancer: Examining mechanism of action and efficacy within the tumor. Urol Oncol 2016;34:182-92.

8. Shelley MD, Kumar S, Wilt T, et al. A systematic review and meta-analysis of randomised trials of neo-adjuvant hormone therapy for localised and locally advanced prostate carcinoma. Cancer Treat Rev 2009;35:9-17.

9. Dreicer R, Magi-Galluzzi C, Zhou M, et al. Phase II trial of neoadjuvant docetaxel before radical prostatectomy for locally advanced prostate cancer. Urology 2004;63:1138-42.

10. Febbo PG, Richie JP, George DJ, et al. Neoadjuvant docetaxel before radical prostatectomy in patients with high-risk localized prostate cancer. Clin Cancer Res 2005;11:5233-40.

Cite this article as: Pignot G, Walz J. Identifying the relevant population for neoadjuvant chemo-hormonal therapy combined with radical prostatectomy. Gland Surg 2020;9(2):495-497. doi: $10.21037 /$ gs.2019.12.22
11. Magi-Galluzzi C, Zhou M, Reuther AM, et al. Neoadjuvant docetaxel treatment for locally advanced prostate cancer: a clinicopathologic study. Cancer. 2007;110:1248-54.

12. Eastham JA, Heller G, Halabi S, et al. LBA-12 CALGB 90203 (ALLIANCE): Radical Prostatectomy with or without neoadjuvant chemohormonal therapy in men with clinically localized, high-risk prostate cancer. J Urol 2019;201:e997.

13. Pignot G, Maillet D, Gross E, et al. Systemic treatments for high-risk localized prostate cancer. Nat Rev Urol 2018;15:498-510.

14. Vale CL, Burdett S, Rydzewska LHM, et al. Addition of docetaxel or bisphosphonates to standard of care in men with localised or metastatic, hormone-sensitive prostate cancer: a systematic review and meta-analyses of aggregate data. Lancet Oncol 2016;17:243-56.

15. Beltran H, Wyatt AW, Chedgy EC, et al. Impact of Therapy on Genomics and Transcriptomics in High-Risk Prostate Cancer Treated with Neoadjuvant Docetaxel and Androgen Deprivation Therapy. Clin Cancer Res 2017;23:6802-11. 